\title{
Symptoms and pathology of experimental bovine tropical theileriosis (Theileria annulata infection)
}

\author{
par B. S. GILL, Y. BHATTACHARYULU et D. KAUR \\ College of Veterinary Science, Punjab Agricultural University, Ludhiana 141004, India
}

\section{Sumimary.}

Bovine tropical theileriosis (Theileria annulata infection) is of great economic importance to several countries of Asia and Africa where millions of cattle are at risk of exposure to this disease. The authors describe symptoms, sequence of appearance of the parasite and pathology of the infection by three virulent strains of the parasite in fully susceptible calves.

Symptoms observed were: enlargement of local lymph gland, fever, haemorrhages on visible mucous membranes and sometime on skin, anaemia and jaundice particularly in subacute and chronic forms of the disease.

The parasite "schizont" was first detected in the swollen local lymph gland draining the site of attachment of ticks, then in other lymph glands which concurred with the onset of fever.

Main post-mortem findings were: oedema and enlargement of, and haemorrhages in lymph glands and spleen, haemorrhages in subcutis and on most of the serous and mucous membranes, on endocardium, pericardium and epicardium, and ulcers in abomasum which rarely extended to intestine, oesophagus, tongue and gums. The microscopic lesions were characterized by hyperplasia of lymphoid cells at the haemopoietic centres in lymph glands and spleen followed by regression and degeneration of the germinal centres. Infiltration by lymphocytes and macrophages was observed in intermysial (heart) and periportal (liver) areas and in interstitial spaces in kidneys. T. annulata parasitises lymphoid cells. It provides stimulus for accelerated production of the cells which results in hyperplasia of the lymphoid tissue. Increased activity of the reticular tissue is a protective phenomenon.

Reçu le 6 juillet 1977. 


\section{Résumé.}

\section{Symptômes et pathologie de la theilériose tropicale bovine expérimentale à Theileria annulata.}

La theilériose tropicale bovine, à Theileria annulata, est d'une grande importance économique dans plusieurs contrées d'Asie et d'Afrique où des millions de têtes de bétail sont exposées à cette affection. Les auteurs décrivent les symptômes, les séquences d'apparition du parasite et la pathologie de l'infection par trois souches virulentes du parasite chez les jeunes veaux réceptifs.

Les symptômes observés sont une hypertrophie locale des ganglions lymphatiques, de la fièvre, des hémorragies sur les membranes muqueuses visibles et parfois sur la peau, de l'anémie et un ictère, en particulier dans les formes subaiguës ou chroniques de la maladie.

Le schizonte parasite a été découvert d'abord dans l'adénome lymphatique local, au niveau de la fixation des tiques, puis dans d'autres ganglions, ce qui coïncidait avec le déclenchement de la fièvre.

Les observations post-mortem les plus importantes sont l'œdème et les hémorragies des giandes lymphatiques et de la rate, les hémorragies sous-cutanées et de la plupart des membranes muqueuses ou séreuses de l'endocarde, péricarde, épicarde, les ulcères de la caillette qui rarement s'étendent jusqu'à l'intestin, l'œesophage, la langue ou les gencives.

Les lésions microscopiques sont caractérisées par une hyperplasie des cellules lymphoïdes dans les centres hématopoiétiques, les ganglions lymphatiques et la rate, suivie de régression et de dégénérescence des centres germinaux. Un infiltration par des lymphocytes et des macrophages a été observée dans les fibres du myocarde, dans les zones périportales du foie et dans les espaces interstitiels du rein.

$T$. annulata parasite les cellules lymphoïdes. Il entraîne une production accélérée de ces cellules d'où résulte une hyperplasie du tissu lymphoïde. Cette activité accrue du tissu réticulaire constitue une réaction de protection contre l'envahissement des parasites.

\section{Introduction}

India has undertaken large-scale programme of upgrading its low yielding indigenous zebu cattle (Bos indicus) by cross-breeding them with the high yielding European breeds of cattle (Bos taurus) for increasing milk production. Similar programmes are afoot in many countries of Asia and Middle East (Adler, 1952; El-Refaii, 1976; Hooshmand-Rad, 1974, 1976; Siddiqui, 1976). Millions of cattle are at risk of exposure to theileriosis in these countries. The disease is posing great threat to the success of their cross-breeding programmes as the exotic and cross-bred cattle are highly susceptible to tropical theileriosis (Theileria annulata infection). The disease may cause up to $80 \%$ mortality and it will be several weeks before the survivors return to the normal production level. 
Sen and Srinivasan (1937) described symptoms and lesions of T. annulata infection produced by inoculation of infective blood into susceptible cattle. Principle symptoms noted were: fever, enlargement of lymph glands, anaemia, icterus and petechiae on visible mucous membranes. The most constant post-mortem findings were: thin and watery condition of blood, oedema of lymph glands and spleen, petechiae on serous membranes and respiratory tract and ulcers in abomasum.

The accounts of microscopic pathology of $T$. annulata infection are scanty. Sergent et al. (1945) briefly described lesions as congestion and haemorrhages in all organs especially liver, spleen and lymph glands and hyperplasia of lymphoid tissue in spleen, lymph glands, liver and kidneys. Prasad et al. (1970) have described infiltration by lymphocytes in the periportal areas of liver, at perivascular and peribronchiolar sites, around glomeruli and in tubules in kidneys and hyperplasia or depletion of lymphocytic cells in lymph glands.

The present authors describe the sequence of symptoms and appearance of the parasite, and macroscopic and microscopic pathology of the infection produced experimentally by the bite of infective ticks.

\section{Materials and Methods}

The experimental animals were cross-bred calves (Red Danish $\times$ Sahiwal or Tharparkar, or Holstein-Friesian $\times$ Sahiwal or Tharparkar), raised in tick-proof rooms from the time of birth. The animals were two to six months old when infected.

The infections were initiated by the bite of one to 30 infective ticks - Hyalomma dromedarii, $H$. anatolicum anatolicum and $H$. detritum released on an ear and a cloth bag tied around it. Three strains of $T$. annulata, one from Hissar (Gill et al., 1974) and one each from Amritsar and Ludhiana, respectively isolated from clinical cases of the disease and which caused up to $75 \%$ mortality were used. The animals were observed daily for symptoms of illness and the rectal temperature recorded morning and evening.

Biopsy material from the lymph gland draining the site of infestation by the ticks, hereafter referred to as the local lymph gland, sucked through a wide bore needle attached to a glass syringe, and blood smears were stained with Giemsa stain and examined under a binocular research microscope. Each smear was examined for about ten minutes before declaring it as free of the parasite. Haemoglobin $(\mathrm{Hb})$ content of the blood was determined with a Sahli haemometer (Hellige Incorporated, 877 Stewart Avenue, Garden City, N.Y.) and packed cell volume (PCV) by the Wintrobe method (Wintrobe, 1967).

Carcases were opened as soon as possible after death, naked-eye lesions noted, pieces of the organs harvested and preserved in $10 \%$ formol saline. These were processed, and five to six microns thick sections cut and stained with haematoxylineosin stain. 


\section{Observations}

In peracute cases of the disease, i.e. when death occurred within eight to ten days of the tick bites or between two to three days of the onset of clinical illness, the animals showed only fever with attendant symptoms and enlargement of the local lymph gland. At this stage, only schizonts could be detected in the lymph gland. No naked-eye lesion was present.

In acute type of the disease, i.e. when death occurred about two weeks after the tick bite or the fifth to seventh day of the clinical illness, fever and the attendant symptoms, swelling of the local lymph gland, and the appearance of schizonts in the biopsy material of the lymph gland and of the theilerial piroplasms in the red blood corpuscles were observed in that order. No definite macroscopic lesions were present in such cases.

In subacute type of the infection, i.e. when the animal died after about two weeks of illness, all the characteristic symptoms and macroscopic lesions were present. The blood showed piroplasms and schizonts. Cases which had survived three to four weeks of illness developed anaemia and generally recovered within about six to eight weeks.

The symptoms and pathology of the disease described below is the composite picture of the observations extending over three years and included some 200 infected animals.

\section{Symptoms}

The cardinal sign of theileriosis was the swelling of the local lymph gland. The swelling commenced on the 5th or 6th day of the infection and gradually increased from two to three times in size by about the 8th to 9th day. Meanwhile, other superficial lymph glands became enlarged. Biopsy material of the lymph gland showed large numbers of lymphoblasts parasitised by schizonts from the 7 th to 12th day onwards. Macroschizonts were the first to appear. They gradually increased in number followed by the appearance of a few extracellular macroschizonts, i.e. bits of cytoplasm enclosing the chromatin particles, and microschizonts. The number of the two types of the schizonts increased progressively till death, or declined to undetectable level in about three weeks in recovered animals. Fever was seen between the 5th and 12th days which concurred with the swelling of the superficial lymph glands. Fever increased markedly after two to three days and kept on fluctuating between 39 and $42^{\circ} \mathrm{C}$. It might persist till death in severe infections, or it might become normal in one to 25 days in the recovered animals. In some animals which were artificially infected with one tick infestation, fever was first observed on the 17 th and 31 st days in two animals.

Intraerythrocytic piroplasms appeared in the peripheral circulation between the 9th and 20th days of the infection. Number of the infected erythrocytes generally increased up to 20 to $30 \%$ but higher rate of parasitisation was reached in acute 
cases terminating fatally. In mild cases, the parasitaemia increased up to about 10 to $15 \%$, persisted for a few days, and decreased to undetectable level in about four to six weeks.

During febrile reaction, the pulse and respiration rates were accelerated, eyelids were swollen, profuse lachrymation occurred and in some cases the eye ball appeared protruding from the socked. Conjunctiva became progressively pale and icteric. Serous nasal discharge occurred which became purulent as the disease progressed. Yellow-coloured loose faeces were sometimes observed. Usually the appetite remained normal till a day or two before death, when the animals went off-feed or refused milk. Despite the normal appetite, the animals became progressively weak, became prostrate toward terminal stage of the illness and lapsed into coma till death. Death usually occurred in about two to three weeks or so after the tick infestation. If the animal had survived, recovery took place in four to eight weeks.

Anaemia became pronounced when the illness took prolonged course. Decrease in $\mathrm{Hb}$ by 12 to $72 \%$ and in PCV by 17 to $71 \%$ was common. In recovered animals, $\mathrm{Hb}$ and $\mathrm{PCV}$ values returned to normal levels in four to eight weeks.

In no case the authors came across bloody urine, indicating haematuria or haemoglobinuria.

\section{Macroscopic pathology}

Head including eyelids showed oedematous swelling. Conjuctiva was pale and petechiated, and in a few cases haemorrhage in the eyeball was seen (fig. 1). Haemorrhagic spots or patches were seen on the skin of ears (fig. 2), inside thighs, in axilla and perineal region, and around anus and on caudal fold. Extensive haemorrhages in subcutis were present which, in some cases, were particularly severe in the axial and perineal regions.

Local lymph gland and prescapular, prefemoral, precrural, submaxillary and mediastinal lymph glands were markedly enlarged and oedematous, and showed extensive haemorrhages on the surface and in the parenchyma.

Haemorrhagic spots or splashes were seen over the pleurae, peritoneum, mesentery and omentum, on serous surface of the stomachs and intenstine (fig. 3) and on the mucous membrane of lips, tongue (fig. 4), gums (fig. 5), hard palate, surface of lungs which were pale, and on pericardium, endocardium and myocardium.

Numerous haemorrhages turning into punched out ulcers with necrotic centre and haemorrhagic border (fig. 7) varying in size up to $1.5 \mathrm{~cm}$. in diameter were seen on the mucosa of abomasum. In some cases, the ulcers were also present in small and large intestine (fig. 8) and oesophagus, and on the tongue and gums.

Liver was much enlarged and showed a few haemorrhagic spots on the surface. Sometime, a few whitish pin-head size spots were seen on its surface. Gall bladder was distended with dark olive-green or brownish-green bile. Rarely, a few heamorrhagic spots or patches were seen on the serous surface.

Spleen was much enlarged and showed petechial haemorrhages or large haemorrhagic spots or patches on the surface and in the paranchyma. 

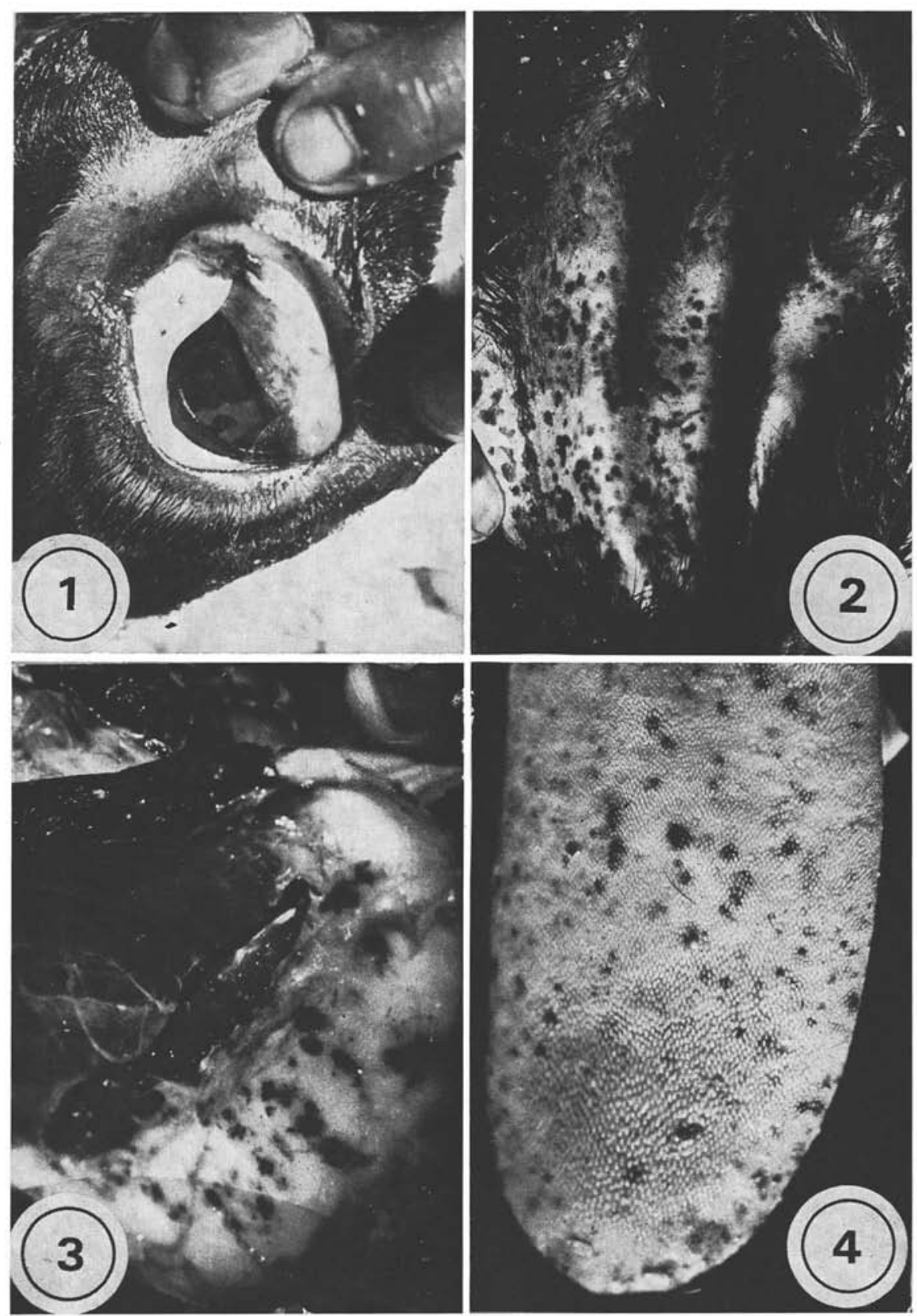

Plate I

FIG. 1. - Photograph showing haemorrhages in the eyeball and petechiae on conjunctiva.

Fig. 2. - Photograph showing haemorrhages on the external ear.

FIG. 3. - Photograph showing haemorrhages on the serous surface of intestine.

FIG. 4. - Photograph showing haemorrhages on tongue.

Fig. 1 to 8 are photographs showing lesions of $T$. annulata infection, and fig. 9 to 12 are photomicrographs of sections of the organs of animals dead of $T$. annulata infection, and stained with haematoxylin-eosin. 

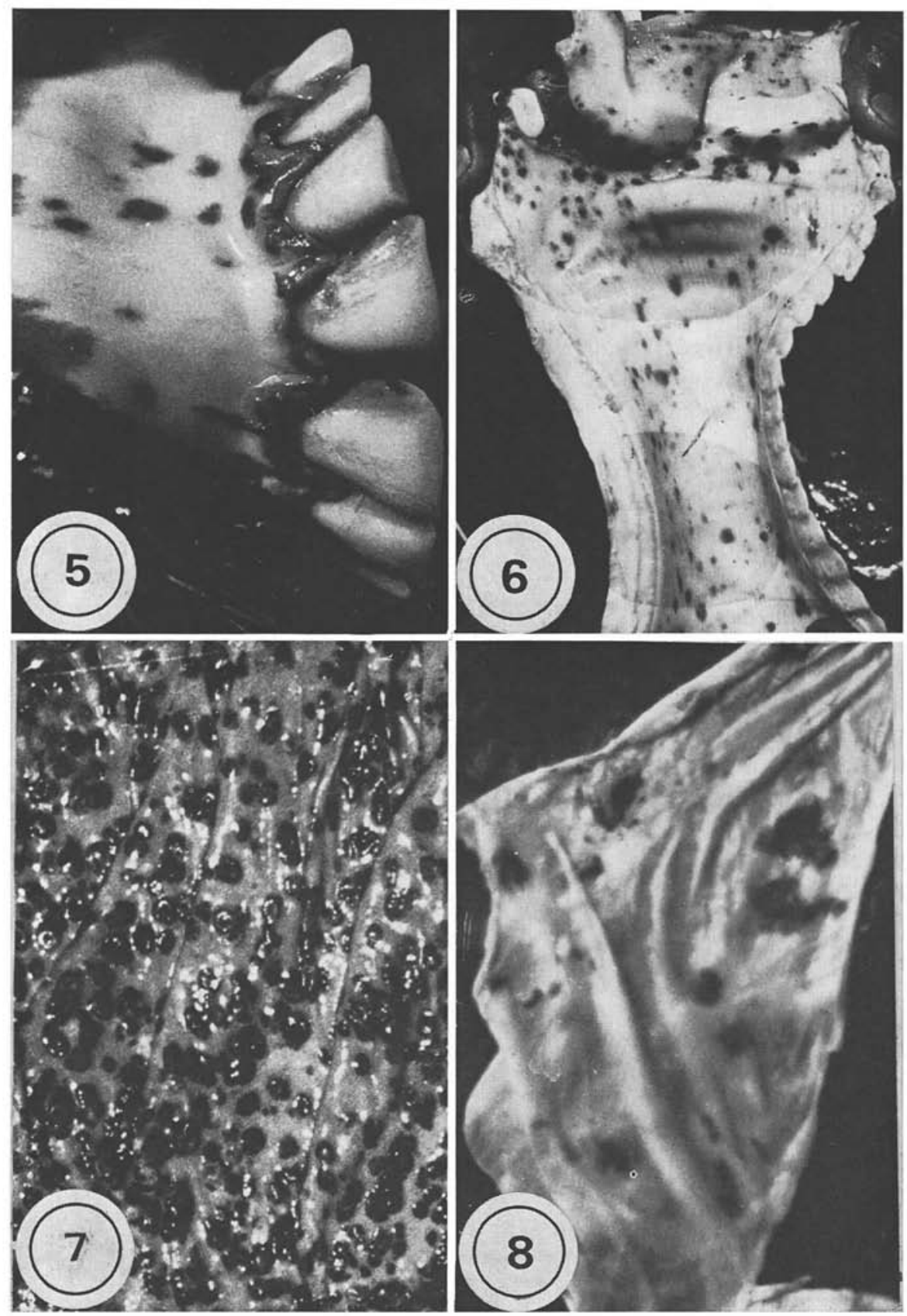

Plate II

Fig. 5. - Photograph showing haemorrhages on the inside of lip and on gums.

Fig. 6. - Photograph showing haemorrhages on the mucous membrane of larynx, epiglottis and trachea.

FIG. 7. - Photograph showing haemorrhages and typical ulcers on mucosa of abomasum. Fig. 8. - Photograph showing haemorrhages on the mucous membrane of intestine. 
Kidneys were slightly enlarged and hyperaemic. Rarely, greyish-white pin-head size spots were seen on its surface. Mucous membrane of the urinary bladder was congested and rarely petechiated.

Brain was slightly congested. Rarely, a few haemorrhagic spots were observed on the piamater.

Intercostal muscles, sternum and xiphoid cartilage also showed large haemorrhagic spots. In subacute cases, visible mucous membranes were yellow in colour.

\section{Microscopic pathology}

Heart showed degeneration of myocardial fibres characterized by loss of cross and/or longitudinal striations, with increased granularity of the sarcoplasm, and diffuse infiltration of intermysial area by a large number of mononuclear cells - lymphocytes and macrophages - which caused atrophy of the surrounding musculature (fig. 9). At places, intermysial oedema or haemorrhage was present.

Lungs showed thickened interalveolar septa with prominent blood vessels and at places haemorrhages in the alveolar spaces.

Kidneys revealed congestion of intertubular vessels and degenerative changes in the lining cells of the tubules. Some of the medullary tubules also revealed red blood cells. Focal areas of infiltration of the interstitial spaces of cortex mostly and of the medulla occasionally by lymphocytes were also present (fig. 10).

Liver showed diffuse infiltration of periportal area by a large number of lymphocytes and in some cases catarrh of the sinuses with early degenerative changes.

Ulcers on the mucosa of the abomasum, tongue, etc. extending to the underlined musculature were present.

Sections cut through haemorrhagic spots of the skin revealed focal haemorrhages with parasitised lymphocytes packed in these areas.

Brain showed mild swelling of vascular endothelial cells, areas of perineuronal and perivascular oedema, satellitosis and areas of gliosis and neuronophagia.

Lymph glands showed almost uniform proliferative changes characterized by diffuse hyperplasia of the lymphoid follicles of cortex some of which showed prominent germinal centres. Occasionally, as a result of the fusion of follicles, the cortex was replaced by a sheet of lymphocytes which often extended into the medul-

\section{Plate III}

FIG. 9. - Section of heart showing degenerative changes in myofibrils, and infiltration of intermysial areas by lymphocytes and marcophages. $\times 200$.

FIg. 10. - Section of cortex of kidney showing focal infiltration by lymphocytes in interstitial spaces and degenerative chages in tubular lining. $\times 400$.

FIG. 11. - Section of liver showing infiltration of periportal areas by lymphocytes, and early degenerative changes in hepatic cells. $\times 100$.

FIG. 12. - Section of local lymph gland showing a follicle infiltrated with eosinophilic amorphous substance in reticular network indicating fibrinoid degeneration. $\times 200$. 


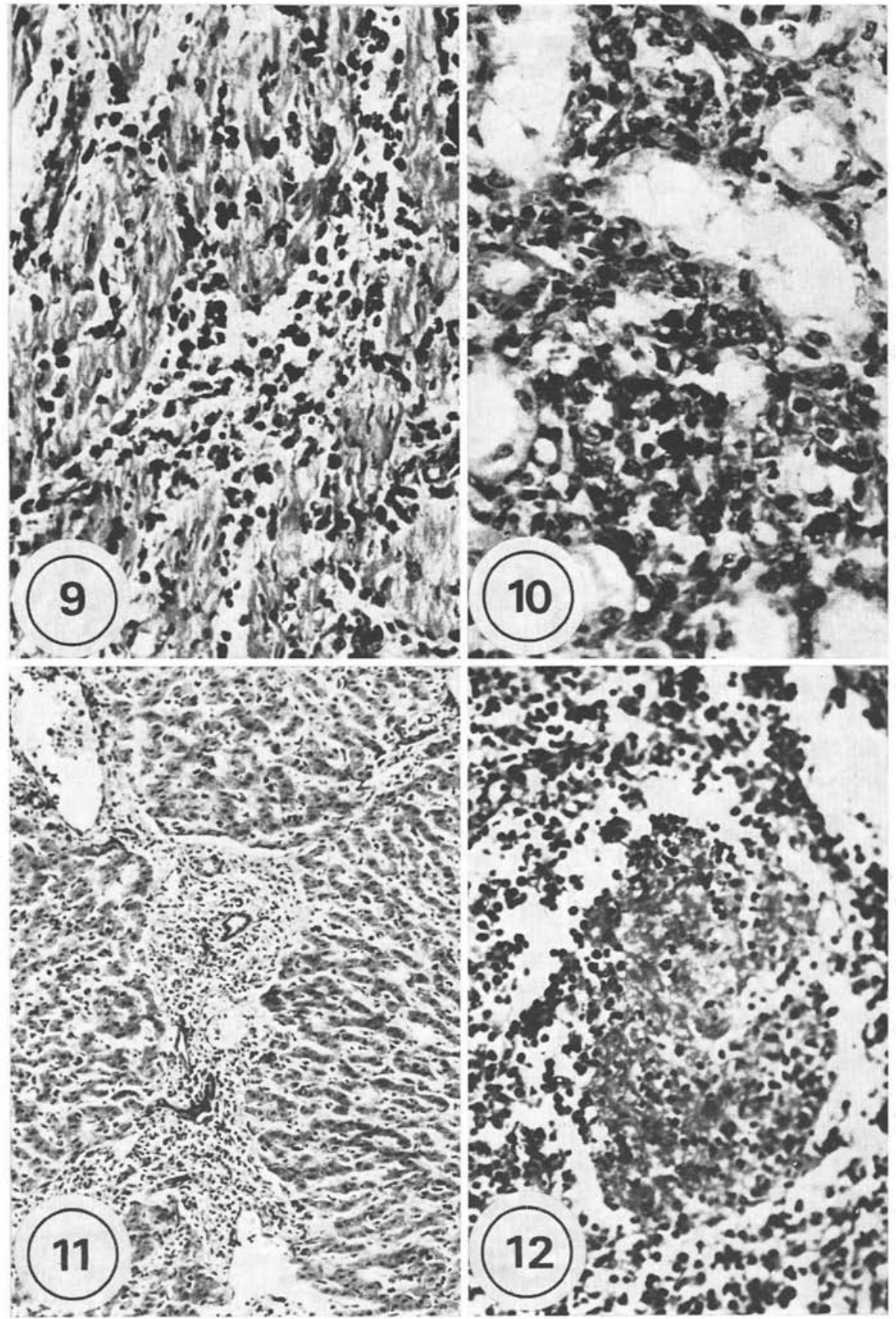


lary zone. The Billroth's cords also showed an increase in the number of lymphocytes. The medullary sinuses showed catarrh with large number of macrophages. Some of the lymph glands showed depletive changes characterized by loss of distinction between cortex and medulla, infiltration with an eosinophilic amorphous substance in the reticular frame-work of the white pulp and occasionally in the surrounding red pulp which has close resemblance to fibrinoid degeneration (fig. 12).

Spleen showed changes similar to those observed in lymph glands. Acute congestion of red pulp and diffuse hyperplastic changes in the reticular cells forming reticular macrophages were seen. These cells showed erythrocytolysis and erythrophagocytosis with evidence of diffuse haemosiderosis of the pulp. The white pulp was apparently unaffected, though overcrowding of the cells in the red pulp gave an appearance simulating atrophy of the white pulp.

\section{Discussion}

Symptoms and severity of theileriosis depend upon virulence and pathogenicity of the strain of the causative agent, the quantum of the infection and the susceptibility status and age of the host. The lesions vary depending upon the severity and duration of the pathological process. As in the present case, the infections produced in laboratory in fully susceptible cattle, by varying doses of the infective inoculum, i.e. by the bite of one to 30 ticks infected with three strains of the parasite, produced widely representative range of symptoms and lesions of the disease. In nature, these conditions vary within wide range so that the resultant picture of the infection varies from mild to severe or peracute form of the disease. The description of symptoms of single natural episodes of $T$. annulata given by various authors reviewed by Neitz (1957), and Gill and Bhattacharyulu (1976) fall within this range. Some symptoms or lesions have been observed by some authors only, e.g. haemorrhagic spots on skin have been described by Tsur-Tchernomoretz et al. (1960), and haemoglobinuria by Neitz (1957) and Gautam et al. (1970).

The reviews which took into account a number of outbreaks presented the total picture of the natural infection. The description of symptoms and macroscopic lesions of the natural disease given by Neitz (1957) tallies with that of the experimental infections given in this article.

The outstanding characteristic of the pathological process in $T$. annulata infection is intense hyperplasia of lymphoid cells at the lymphopoietic centres, followed by depletion of lymphocytes at, and disorganization and degeneration of these centres. The accelerated production and reproduction of lymphoid cells coincide with the parasitisation of the lymphocytes by schizonts of $T$. annulata (unpublished observations) and T. parva (Hulliger et al., 1964). The changes begin at the local lymph gland and later extend to other lymph glands and spleen as the parasitisation progresses. The regenerative attempt to produce lymphocytes extended to kidney and liver as manifest by lymphocytic infiltration in these organs. 
The increased macrophage formation is the protective tissue reaction to deal with the parasite - schizonts. With the progress of the infection, the lymphopoit tic propensity is exhausted as evident from depletion of the lymphoid cells at the germinal centres leading to their regression and degeneration. The above pathological process is essentially the same as observed in $T$. parva which has been summ 2d up and thoroughly investigated recently by Barnett (1960) which explains similarity in symptoms and lesions of the two diseases (Neitz, 1957).

\section{ACKNOWLEDGEMENTS}

The observations recorded in this article were made under the Indian Council of Agricultural Research, New Delhi ad-hoc research scheme entitled «Investigation into Bovine Tropical Theileriasis». The authors thank Dr. P. K. Ramchandran, Professor of Pathology, Indian Veterinary Research Institute, Izatnagar, U.P., India for assistance in observations on microscopic pathology.

\section{Bibliography}

Adler (S.), 1952. - Les piroplasmoses chez les Bovidés en Israël. Bull. Off. int. Epiz., $38,570-574$.

BarnetT (S. F.), 1960. - Connective tissue reactions in acute fatal East Coast fever (Theileria parva) of cattle. J. Inf. Dis., 107, 253-282.

El-Refan (A. H.), 1976. - An outline of theileriosis in Egypt. A paper presented af the International Conference on Theileriosis, Nairobi, Kenya, December 7 to 9, 1976.

Gautam (O. P.), Sharma (R. D.) et Kalra (D. S.), 1970. - Theileriasis in exotic breeds and a Sahiwal calf. Indian Vet. J., 47, 78-83.

Gill (B. S.) et Bhattacharyulu (Y.), 1976. - Bovine theileriosis in India. A paper presented at the International Conference on Theileriosis, Nairobi, Kenya, December 7 to $9,1976$.

Gill (B.S.), KaUR (D. M.) et Bhattacharyulu (Y.), 1974. - Transmission of Theileria annulata through the tick Hyalomma detritum (Schulz, 1919). Bull. Off. int. Epiz., 81, 805-811.

Hooshmand-Rad (P.), 1974. - Blood protozoan diseases of ruminants. Bull. Off. int. Epiz., 81, $779-792$.

Hooshmand-RAD (P.), 1976. - Theileriosis in ruminants of Iran. A paper presented at the International Conference on Theileriosis, Nairobi, Kenya, December 7 to 9, 1976.

Hulliger (L.), Wilde (J. K. H.), Brown (C. G. D.) et Turner (L. M.), 1964. - Mode of multiplication of Theileria in cultures of bovine lymphocyte cells. Nature (London), 203, 728-730.

NeITZ (W. O.), 1957. - Theileriosis, gonderioses and cytauxoonoses: A review. Onderstepoort J. Res., 27, 275-430. 
Prasad (M.), Ansari (S. A.) et Kuppuswamy (P. B.), 1970, - Pathology of bovine theileriasis. Indian Vet. J., 40, 622-625.

Sen (S. K) et Srinivasan (M. K.), 1937. - Theileriasis of cattle in India. Indian J. Vet. Sci., 7, 15-37.

Sergent (E.), Donatien (A.), Parrot (L.) et Lestoquard (F.), 1945. - Etudes sur les piroplasmoses bovines. Inst. Pasteur d'Algérie, Alger. Cited by Neitz (1957).

SiddiQui (E. H.), 1976. - The effects and importance of diagnosis of theileriosis in livestock industry of Pakistan. A paper presented at the International Conference of Theileriosis, Nairobi, Kenya, December 7 to 9, 1976.

Tsur-Tchernomoretz (I.), Davidson (M.) et Weissenburg (I.), 1960. - Two cases of bovine theileriasis ( $T h$. annulata) with cutaneous lesions. Refuah Veterinarith, 17, 99-100.

Wintrobe (M. M.), 1967. - Clinical Haematology, Lea and Febiger, édit., Philadelphia, U.S.A. 